\title{
Technical and economic efficiency of materials using 3D-printing in construction on the example of high-strength lightweight fiber- reinforced concrete
}

\author{
Aleksandr Inozemtcev* and Thanh Qui Duong \\ Moscow State University of Civil Engineering, Yaroslavskoye shosse, 26, Moscow, 129337, Russia
}

\begin{abstract}
The technology of 3D printing in construction causes great interest by increasing the speed and accuracy of building structures, reducing labor costs, construction waste and risks to human health. Today, the principles of 3D-printing actually are interpretations of the existing monolithic or prefabricated technology. This requires the development of high-performance materials for the extrusion of functional structures. The paper shows the example of the effectiveness application of high-strength lightweight fiber-reinforced concrete with a complex of structural and thermal insulation properties in 3D-printing technology. It has been established that the use of high-strength lightweight fiber-reinforced concrete for 3D-printing provides an increase in the useful space by $1.1 . .5 .4 \%$, a reduction in the material consumption of wall structures by $6.1 \ldots 19.1 \%$ and a reduction in the number of machine hours by $29.6 \ldots 37.4 \%$. The total technical and economic efficiency of using such a material for a standard or optimized wall section is $30.8 \ldots . .50 .4 \%$.
\end{abstract}

\section{Introduction}

In construction, 3D-printing technology is of great interest due to possibility of ensuring high speed and accuracy of construction, reducing labor costs, construction waste and human health risks, as well as potential to expanding configuration of construction projects and their elements. It was shown [1] today there are many variations of 3D-printers using principle of layer-by-layer extrusion of materials that can be divided on two categories based on a configuration of equipment (frame or crane type, mobile or stationary configuration) and on a type of used material. Various materials such as cement composites, polyurethane foam and ceramics can be used like "ink" (printing materials) for 3D-printers. In addition, there are industrial projects of the buildings constructed from soil containing clay, silt, sand, crushed rice straw, rice husk and lime [2]. To a greater extent, these projects are demonstrated of versatility for 3D-printing equipment. Nevertheless, today there is no any comprehensive solution to overcome shortcomings of 3D-printing technology, one of which is non-functionality of printed elements. The structures erected by

\footnotetext{
Corresponding author: InozemcevAS@mgsu.ru
} 
3D-printer function as a formwork or a self-supporting enclosing structure due to low performance characteristics of used materials..

Basic principle of 3D-printing technology implemented by equipment producer is a printing of formwork from mixture on a mineral binder (Fig.1) or polymer (Fig. 2) filling cavities with structural material. It means that advantages of new construction principle are applicable only for auxiliary elements of building. It is decline inherent potential of the 3Dprinting technology.

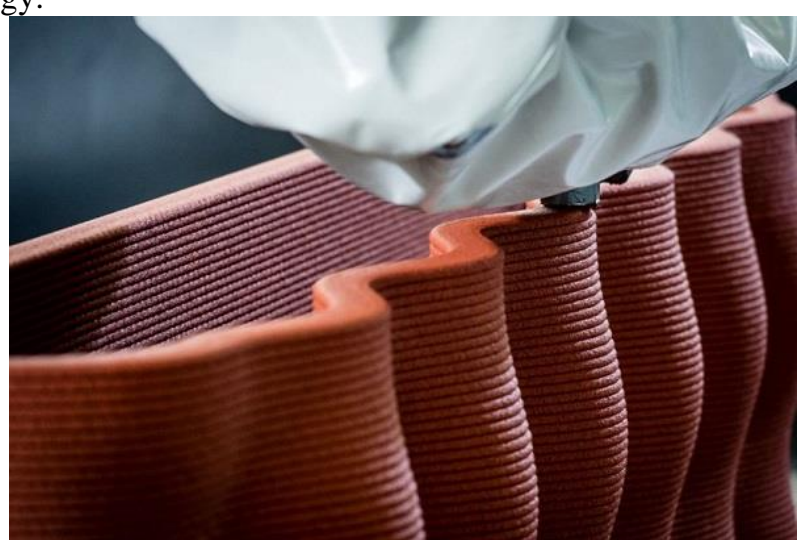

Fig. 1. The process of permanent printing formwork using 3D-printer Sika [3].

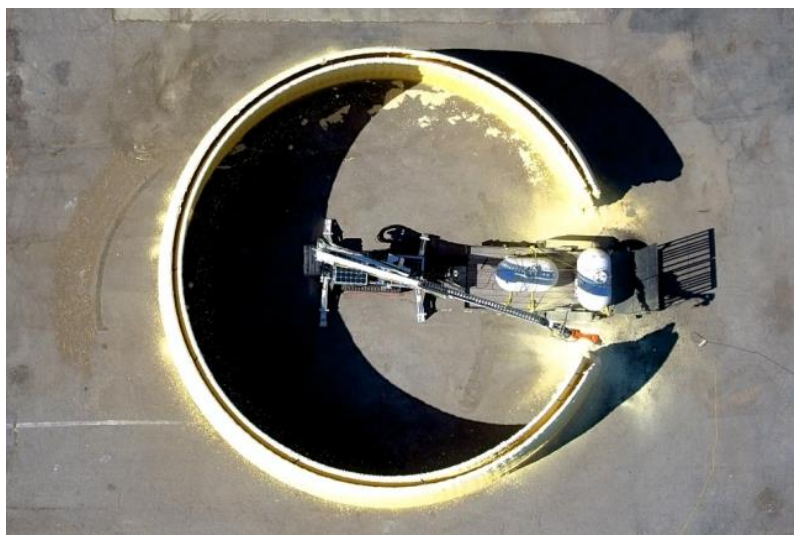

Fig. 2. The process of permanent printing formwork using 3D-printer MIT [4].

In construction, 3D-printing technology should be based on general technological principles and requirements for materials and structures. In spite of some variations, overall tendency for 3D-printing materials is applying cement systems with fine-grained aggregate up to $4 \mathrm{~mm}$, mineral additives, microfiber, anti-shrink chemical additives and adjustment regulators [1]. These materials are heavy concrete with average density from 2100 to 2200 $\mathrm{kg} / \mathrm{m}^{3}$ and compressive strength more than $25 \mathrm{MPa}$. Moreover, standard cross-section of outer walls that made by 3D-printing with cement composites can be attributed to multilayer structure (Fig. 3) with 4-5 formwork ranges. The space between them is filled with structural concrete and thermal insulation material, such as polystyrene or polyurethane foam. 


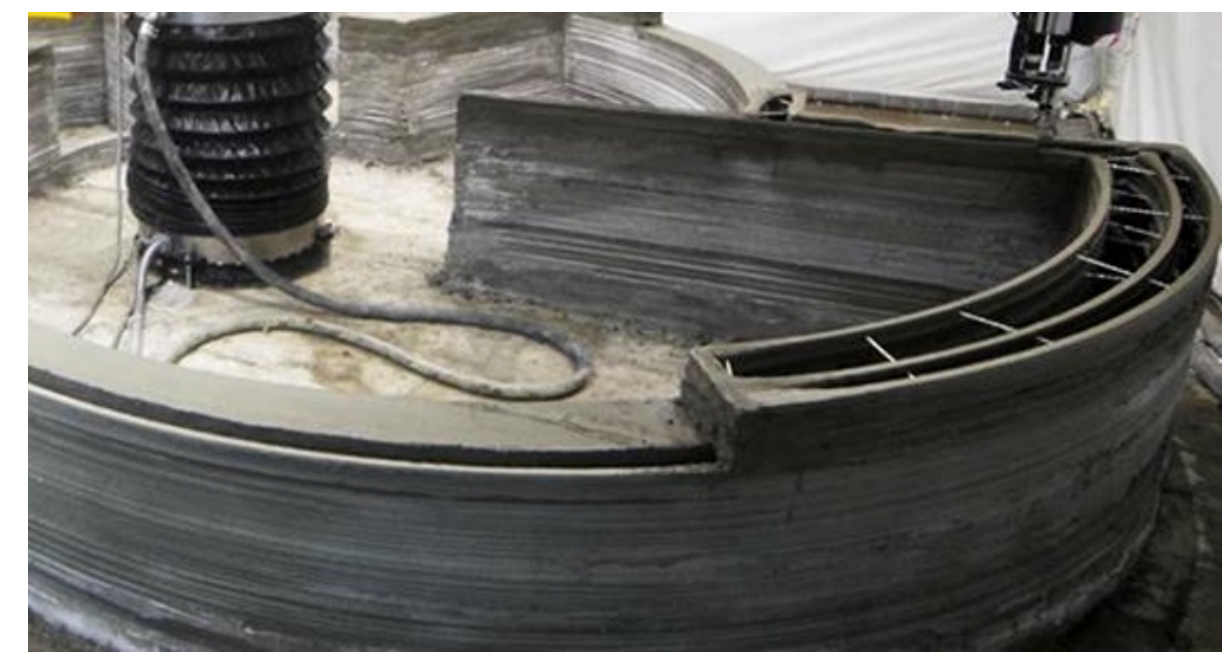

Fig. 3. General outer appearance of building walls structure made by using 3D-printing technology $[5]$.

The above-mentioned technological solutions for 3D-printing definitely show economic efficiency in comparison with traditional approaches in construction, at least for low-rise construction. However, implemented principle is an interpretation of monolithic construction technology of buildings and it is not an independent solution for construction. In this regard, it is promising approach that the extrusion is precisely carried out in order to build functional structures, which requires using modern materials with high performance properties.

Outer structures of buildings and constructions should have a high bearing capacity and sufficient thermal insulation characteristics. The requirements of materials for 3D-printing technology should take into account both the characteristics of mixtures in extrusion process and the properties of composite.

Thus, the using of multifunctional materials combinated structural and thermal insulation properties for 3D-printing could actualize functionality principle of printed elements in building structures and improve efficiency of this technology.

In [6], it is shown that introduction of a new material is advisable both under condition of superiority performance properties and significant reduction in the volume of product (construction). Furthermore, the decreasing in average density of material is an important factor in reducing requirements for geometry of product [6].

High-strength lightweight fiber-reinforced concrete (HSLWFC) has a universal combination of physical, mechanical, thermal and operational properties [7]. This concrete filled with hollow microspheres has a closed pore structure, which has combination with optimized cement-mineral composition and special additives. It provides a low average density of less than $1500 \mathrm{~kg} / \mathrm{m}^{3}$ and high strength up to $70 \mathrm{MPa}$. With additional advantages, HSLWFC has a low thermal conductivity less than $0.60 \mathrm{~W} / \mathrm{m} \cdot{ }^{\circ} \mathrm{C}$ [8]. In [9] the calculations indicate that economic efficiency of construction could reach to $30 \%$ by increasing number of storeys and entire advantageous area of building when designing a building of high-strength lightweight concrete with average density of $1300-1500 \mathrm{~kg} / \mathrm{m}^{3}$.

The estimating effectiveness of using high-strength lightweight fiber-reinforced concrete in 3D-printing technology was done by several options of walls construction of a conditional residential facility with an area of $100 \mathrm{~m}^{2}$ and layout according to Fig. 4 . 


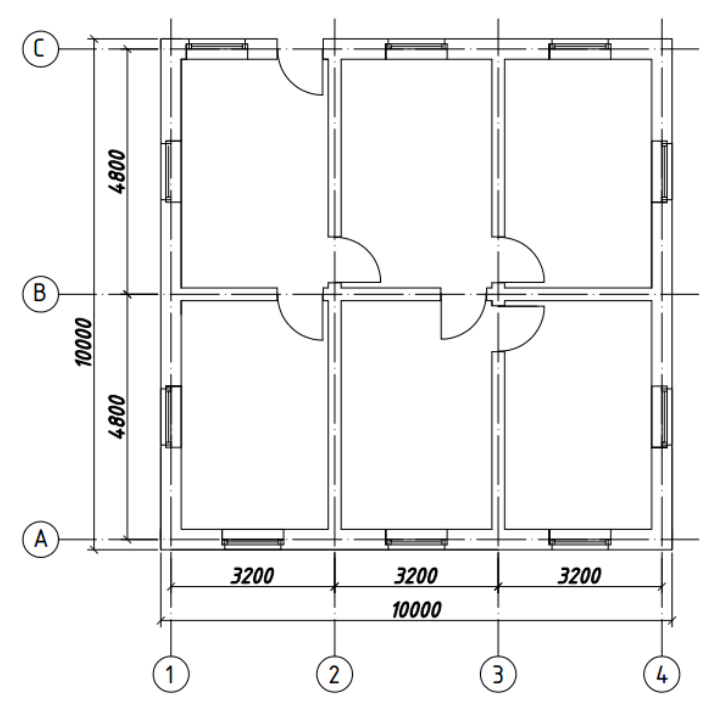

Fig. 4. Model plan of building constructed by using 3D-printing technology.

Suppose that the conditional 3D-printer is used for construction of building with following averaged technical capabilities given in table 1 .

Table 1. Technical characteristics of conditional 3D-printer.

\begin{tabular}{clc}
\hline № & \multicolumn{1}{c}{ Indicator } & Value \\
\hline 1 & Maximum print distance, $\mathrm{m}$ & 8.5 \\
2 & Maximum operating zone, $\mathrm{m}^{2}$ & 130 \\
3 & Print speed, m/min & $5-10$ \\
4 & Volume of supply, $1 / \mathrm{min}$ & 30 \\
5 & Average energy consumption, $\mathrm{kWh}$ & 8 \\
6 & Size of extrusion nozzle: & \\
& - Width, $\mathrm{m}$ & 0.05 \\
& - Height, $\mathrm{m}$ & 0.03 \\
\hline
\end{tabular}

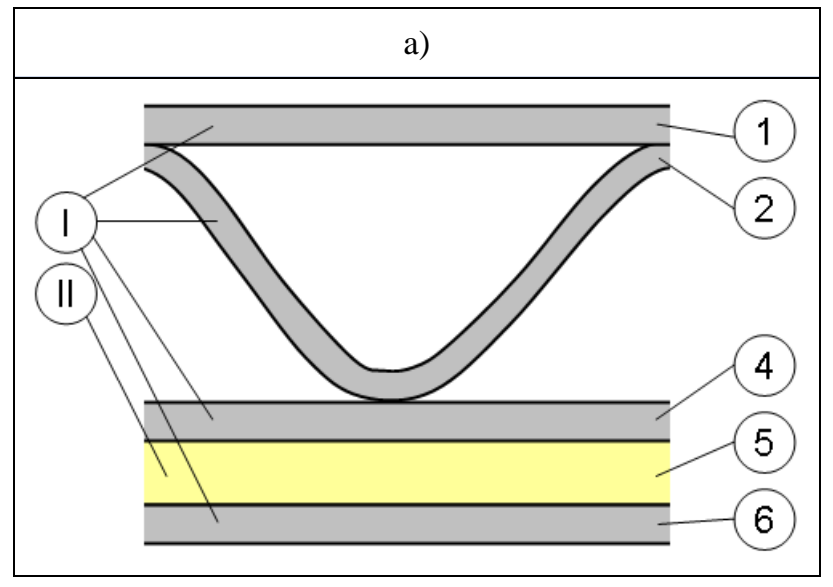




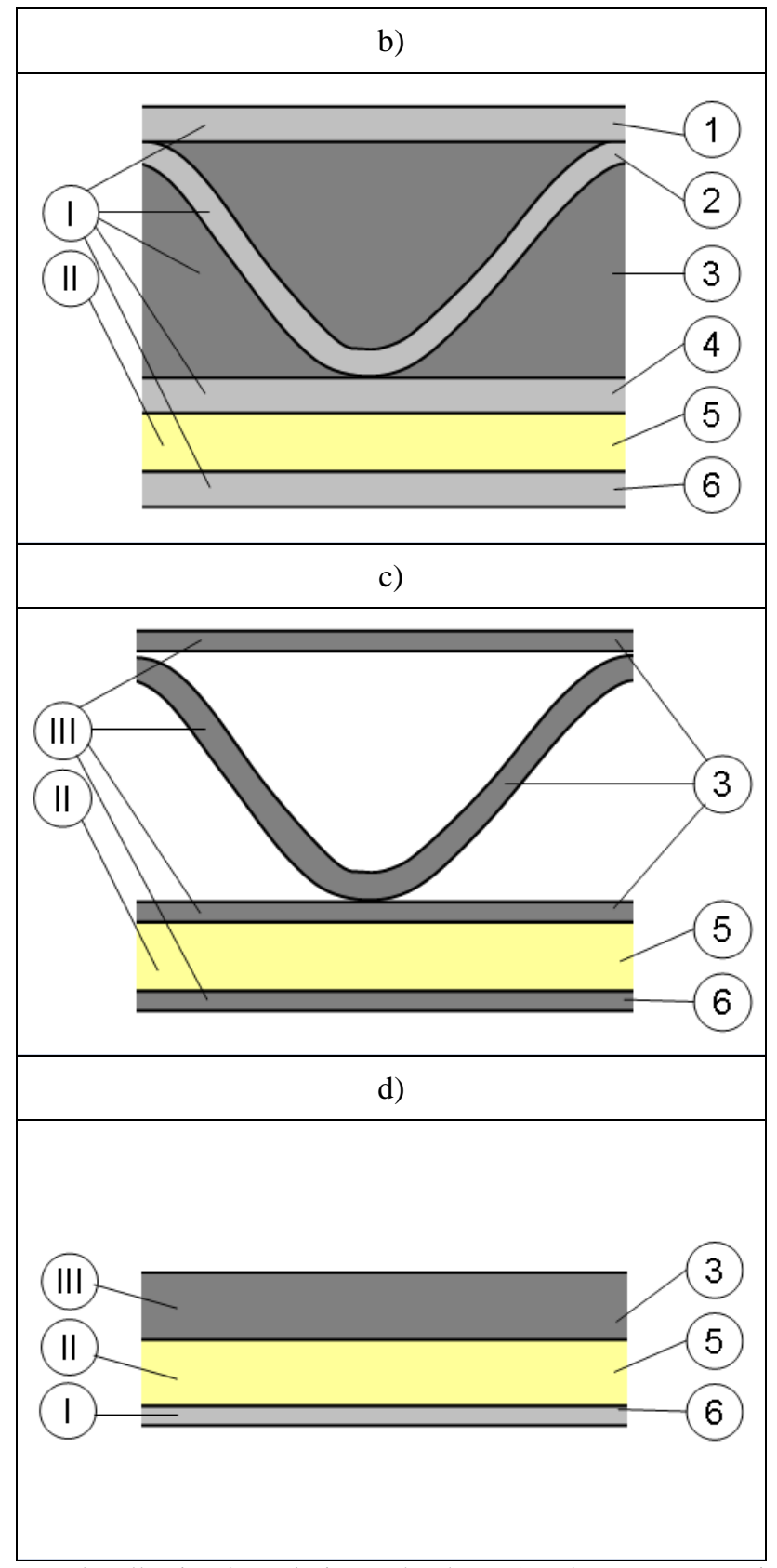

Fig. 5. Type of structural wall using 3D-printing technology: 1 and 6-outer-protective layer; 2 and 4inner layer; 3-bearing layer; 5-thermal insulation layer; I-heavy concrete; II-polyurethane foam; IIIhigh-strength lightweight fiber-reinforced concrete.

Comparative analysis is performed with following design features and materials:

Type 1 - The structure includes four printed layers of formwork made of heavy concrete and one layer of filling polyurethane foam (Fig. 5a);

Type 2 - The structure includes four printed layers of heavy concrete formwork, one concrete layer of the same brand and the last layer of filling polyurethane foam (Fig. 5b); 
Type 3 - The structure includes four printed layers of formwork made of high-strength lightweight fiber-reinforced concrete and one layer of filling polyurethane foam (Fig. 5c);

Type 4 - The structure includes two printing layers: a carrier-layer of high-strength lightweight fiber-reinforced concrete and a protective-layer of heavy concrete; the third one is a layer of filling polyurethane foam (Fig. 5d).

In accordance to this figure, for each type of structures, we use total thickness of insulation layer about $0.1 \mathrm{~m}$, made by using polyurethane foam filled grade D50 and thermal conductivity $0.03 \mathrm{~W} / \mathrm{m}^{\circ}{ }^{\circ} \mathrm{C}$. The heavy concrete with an average density approximately about $2250 \mathrm{~kg} / \mathrm{m}^{3}$ and a strength of $25 \mathrm{MPa}$ is both the printing and filling material for type 1 and 2. The high-strength lightweight fiber-reinforced concrete with average density of $1400 \mathrm{~kg} / \mathrm{m}^{3}$ and strength of $60 \mathrm{MPa}$ is used for types 3 and 4 , except for protective-layer (type 4).

Considering the strength properties of materials used for each type of structures, the thickness of each layer is selected in accordance with the maximum load which is able to carry the total cross-section of all bearing walls. According to accepted perimeter of building (Fig. 5) and cross section of extrusion nozzle (table 1) the maximum support area of walls is $13.4 \mathrm{~m}^{2}$ where structure is type 2 of construction and has concrete strength of 25 $\mathrm{MPa}$. This area provides a bearing capacity of wall contour about 33.5 tons. On this basis, the thickness of walls produced by HSLWFC should be taken to the determined level to provide identical load-carrying capacity (table 2). As a result the thickness of printed carrier-layers will be $0.1 \mathrm{~m}$ for types 3 and 4 . It means that the cross section of print nozzle is necessary to reduce to a width of $0.025 \mathrm{~m}$ for each layer of type 3 and to $0.1 \mathrm{~m}$ for type 4 .

Table 2. The characteristics of wall structure constructed by 3D-printing method.

\begin{tabular}{|c|c|c|c|c|c|}
\hline \multirow{2}{*}{ № } & \multirow{2}{*}{ The purpose of the layer } & \multicolumn{4}{|c|}{ Thickness of layer, m } \\
\hline & & Type 1 & Type 2 & Type 3 & Type 4 \\
\hline 1 & Outer-protective & 0.05 & 0.05 & 0.025 & - \\
\hline 2 & Inner & 0.05 & 0,05 & 0.025 & - \\
\hline 3 & Carrier & - & 0.15 & - & 0.10 \\
\hline 4 & Inner & 0.05 & 0.05 & 0.025 & - \\
\hline 5 & Thermal insulation & & & 0 & \\
\hline \multirow[t]{2}{*}{6} & Outer-protective & 0.05 & 0.05 & 0.025 & 0.025 \\
\hline & Total & 0.40 & 0.40 & 0.325 & 0.225 \\
\hline
\end{tabular}

According to table 2, both the configuration of walls and the total thickness is changed and forms a bigger useful space on an identical area of the building (fig. 4 and table 3). At the same time, the using more durable materials in formwork allows to reduce the consumption of concrete compared to type 1 and type 2 respectively by almost 30 and 55\% and give them functional properties. The design advantage of type 3 is using just one type of material for 3D-printer's "ink" that provides greater processability and reduction of material costs during preparation and construction. It can be seen that design of type 4 allows to increase the useful space of building to approximately $5 \mathrm{~m}^{2}(5.4 \%)$. 
Table 3. Technical features of 3D-printed building using different types of wall structures and materials.

\begin{tabular}{|c|c|c|c|c|c|}
\hline \multirow{2}{*}{ № } & \multirow{2}{*}{ Characteristic } & \multicolumn{4}{|c|}{ Significance for design } \\
\hline & & Type 1 & Type 2 & Type 3 & Type 4 \\
\hline 1 & Length, m & \multicolumn{2}{|c|}{9.3} & 9.35 & 9.55 \\
\hline 2 & Width, m & \multicolumn{2}{|c|}{9.3} & 9.35 & 9.55 \\
\hline 3 & Perimeter of outer walls, $\mathrm{m}$ & \multicolumn{2}{|c|}{37.2} & 37.4 & 38.2 \\
\hline 4 & Perimeter of inner walls, $\mathrm{m}$ & \multicolumn{2}{|c|}{27.4} & 27.7 & 28.3 \\
\hline 5 & Useful area, $\mathbf{m}^{2}$ & \multicolumn{2}{|c|}{86.5} & 87.4 & 91.2 \\
\hline 5.1 & Increase, $\%$ & \multicolumn{2}{|c|}{-} & 1.1 & 5.4 \\
\hline 6 & Material consumption, $\mathrm{m}^{3}$ & & & & \\
\hline 6.1 & - Heavy concrete (25 MPa) & 30.62 & 47.7 & - & 2.37 \\
\hline 6.2 & - Polyurethane Foam (D50) & \multicolumn{4}{|c|}{9.5} \\
\hline \multirow[t]{2}{*}{6.3} & - HSLWFC (60 MPa) & - & - & 21.6 & 17.4 \\
\hline & Total change, $\%$ & - & +55.6 & -29.6 & -37.4 \\
\hline
\end{tabular}

Note: Taking into account the volume of windows and doors.

The technical advantages of solutions using high-strength lightweight fibrous concrete (type 3 and 4) are obviously prerequisite for economic benefits, which is determined by difference in cost of materials (table 4). In this way, the reducing of consumption of concrete in construction of thinner structures at a higher cost of HSLWFC compared to basic technology of 3D-printing provides an economic effect about $19.1 \%$ per $100 \mathrm{~m}^{2}$ of area.

Table 4. Economic features of construction site using 3D-printing technology and different types of wall structures and materials.

\begin{tabular}{|c|c|c|c|c|c|c|}
\hline \multirow{2}{*}{ № } & \multirow{2}{*}{ Characteristic } & & \multicolumn{4}{|c|}{ Significance for design } \\
\hline & & & Type 1 & Type 2 & Type 3 & Type 4 \\
\hline 1 & Cost of materials, thousand USD & & & & & \\
\hline 1.1 & - Heavy concrete (25 MPa) & & 3.54 & 4.55 & - & 0.27 \\
\hline 1.2 & - HSLWFC (60 MPa) & & - & - & 3.32 & 2.59 \\
\hline 1.3 & & Total: & 3.54 & 4.55 & 3.32 & 2.86 \\
\hline 2 & Difference, thousand USD & & - & 1.02 & 0.21 & 0.67 \\
\hline 3 & Economizing, \% & & - & -28.9 & +6.1 & +19.1 \\
\hline
\end{tabular}

Note: Price of heavy concrete for formwork adopted 115.5 USD, heavy concrete for pouring into the cavity - 58.5 USD, high strength lightweight fiber-reinforced concrete 154.0 USD.

The reducing of consumption of used materials saves the total cost and reduces duration of work with these materials. Calculations show that using HSLWFC in standard version of structure (type 3) and with a decrease in the number of layers (type 4) provides reduction in duration of concrete work (table 5). The using durable material can to reduce the duration of building walls of construction to $37.4 \%$. 
Table 5. Duration of concrete mix laying.

\begin{tabular}{|c|c|c|c|c|c|}
\hline \multirow{2}{*}{ № } & \multirow{2}{*}{ Characteristic } & \multicolumn{4}{|c|}{ Significance for design } \\
\hline & & Type 1 & Type 2 & Type 3 & Type 4 \\
\hline 1 & The duration of printing, hours & \multicolumn{2}{|c|}{17.0} & 12.0 & 10.7 \\
\hline 2 & $\begin{array}{l}\text { The cost of work with printer, thousand } \\
\text { USD }\end{array}$ & \multicolumn{2}{|c|}{1.31} & 0.92 & 0.82 \\
\hline 3 & Difference, thousand USD & \multicolumn{2}{|c|}{-} & 0.38 & 0.48 \\
\hline 4 & Economizing, $\%$ & \multicolumn{2}{|c|}{-} & +29.6 & +37.4 \\
\hline
\end{tabular}

Note: The specific cost of printer per hour is 77.0 USD.

Therefore, using more durable materials leads to more rational use of 3D-printed elements and provides structural advantages of constructed object. It is obvious that in order to achieve economic effect described above, heavy high-strength fine-grained concretes can be used as printing material (ink). Notwithstanding high density of concrete makes it difficult to solve problem of maintaining volume of layers under its own weight in printing process and require a greater margin of safety in construction of multi-storey building. Table 6 shows differences in building structures achieved through the use of printed material with other functional properties. Therefore, using high-strength lightweight concrete in addition to simplifying technological task of smooth extruded layers can reduce weight of one floor by more than $70 \%$ at a lower wall thickness, but identical to carrier. It will not only create conditions for economical construction of multi-storey buildings by 3D-printing (compared to high-strength heavy concrete), but also speed up process. In addition, using dense high-quality concrete instead of HSLWFC requires adjusting thickness of insulation. In considered variants, in spite of different thickness of walls, the equal load-bearing and thermal insulation characteristics are ensured. The effectiveness of using high-strength lightweight concrete in construction of multi-storey buildings is demonstrated in [9].

Table 6. Structural properties depending on material properties for 3D-printing.

\begin{tabular}{clcccc}
\hline \multirow{2}{*}{ № } & \multirow{2}{*}{ Characteristic } & \multicolumn{4}{c}{ Significance for design } \\
\cline { 3 - 6 } & & Type 1 & Type 2 & Type 3 & Type 4 \\
\hline 1 & Specific weight of one floor, $10^{3} \mathrm{~kg}$ & 69.4 & 107.7 & 30.7 & 29.3 \\
2 & Wall thickness, $\mathrm{m}$ & 0.40 & 0.40 & 0.33 & 0.225 \\
4 & Outer wall heat transfer resistance, $\mathrm{m}^{2} .{ }^{\circ} \mathrm{C} / \mathrm{W}$ & 3.49 & 3.57 & 3.52 & 3.54 \\
\hline
\end{tabular}

Thus, the obvious structural advantages set up overall economic feasibility of using multifunctional materials, such as high-strength light fiber-reinforced concrete in 3Dprinting technology. Table 7 shows economic indicators of proposed solutions.

Table 7. Economic efficiency of multifunctional materials in 3D-printing.

\begin{tabular}{llcccc}
\hline \multirow{2}{*}{ № } & \multicolumn{4}{c}{ Sharacteristic } & \multicolumn{3}{c}{ Significance for design } \\
\cline { 3 - 6 } & & Type & Type & Type & Type \\
& & 1 & 2 & 3 & 4 \\
\hline $1 \quad \begin{array}{l}\text { The cost of one floor construction }{ }^{*}, \text { thousand } \\
\text { USD }\end{array}$ & 5.30 & 6.83 & 4.98 & 4.29 \\
2 & Useful area of one floor, $\mathrm{m}^{2}$ & \multicolumn{2}{c}{86,5} & 87,4 & 91,2
\end{tabular}


3 The cost of one floor ${ }^{* *}$, thousand USD

\begin{tabular}{cccc}
\multicolumn{2}{c}{13.32} & 13.46 & 14.04 \\
8.02 & 6.49 & 8.48 & 9.76 \\
\hline \multirow{2}{*}{-} & - & 1.99 & 3.27 \\
& - & $\mathbf{3 0 . 8}$ & $\mathbf{5 0 . 4}$ \\
\hline
\end{tabular}

4 Revenue, thousand USD

5 Economic effect, thousand USD

6 Economic effect, $\%$

Notes: ${ }^{*}$ - taking into account overhead costs $50 \%$ of the cost of materials and works, ${ }^{* *}$ The price of $1 \mathrm{~m}^{2}$ is 154 USD.

As shown in table 7 the cost of construction of a facility for types 3 and 4 is comparable to type 1 , but significantly more cost-effective than to type 2 . At the same time, based on the original principle set up in technology of contour construction as a construction technology of affordable housing $[10,11]$ At the same time, based on the original principle set up in technology of contour construction as a construction technology of affordable housing the cost of $1 \mathrm{~m}^{2}$ should be 154 dollars. Then proposed solution for type 3 and 4 can reach a greater economic potential than common today's technologies. The total economic effect for considered conditional object of $100 \mathrm{~m}^{2}$ is more than $50 \%$.

Nevertheless, despite the technical and economic feasibility of using materials reviewed, it should be confirmed that unresolved issues of ensuring monolithic (layer-bylayer connectivity) and implementation of reinforcement in 3D-printing technology request the task of finding complex recipe and technological solutions for the construction of multistorey buildings.

\section{Conclusion}

It is shown that the using of multifunctional high-strength lightweight fiber-reinforced concrete, due to complex combination of performance properties allows to optimize design of elements made by 3D-printing. Furthermore, the using such materials allows to implement principle of layer extrusion for functionally important parts of a construction object. The changing of the geometric characteristics and shape of 3D-printed layers, provided by the properties of materials, is an essential factor to achieve more economic solutions. Thus, it has been established that the use of high-strength lightweight fiberreinforced concrete for 3D-printing provides an increase in the useful space by $1.1 \ldots 5.4 \%$, a reduction in the material consumption of wall structures by $6.1 \ldots 19.1 \%$ and a reduction in the number of machine hours by $29.6 \ldots 37.4 \%$. The total technical and economic efficiency is from 30.8 to $50.4 \%$.

The work was carried out within the framework of the agreement No. 14.583.21.0072 on granting subsidies for the implementation of the federal target program "Research and development in priority areas for the development of the scientific and technological complex of Russia for 2014-2020" (project identifier - RFMEFI58318X0072) with the financial support from the Ministry of Education and Science of the Russian Federation.

\section{References}

1. Inozemtcev A S, Korolev E V, Duong T Q 2018 Vestnik MSGU 7 (118) pp 863-876

2. 3dtoday.ru [Internet] the company WPAS from Italy printed a house of land and straw for 900 euros, [cited 24.01.2019] Available from: https://3dtoday.ru/blogs/dddcopygmail-com/the-company-wpas-from-italy-printed-a-house-of-earth-and-straw-for-900

3. 3dtoday.ru [Internet] 3D-printing technology from concrete of Sika company received the award of the international competition [cited 25.12.2018] Available from: http://3dtoday.ru/blogs/news3dtoday/the-technology-of-3d-printing-of-concrete-by- 
sika-received-the-award-o

4. MIT [Internet] 3-D printing offers new approach to making buildings [cited 25.12.2018] Available from: http://news.mit.edu/2017/3-d-printing-buildings-0426

5. Apis Cor [Internet] the first house was printed in Russia [cited 25.12.2017] Available from: http://apis-cor.com/about/news/first-house

6. Korolev E V, Chevychalov A A 2012 Nanotechnology in construction 2 pp 25-32

7. Inozemtcev A S, Korolev E V 2014 High-strength lightweight fiber-reinforced concrete Patent RF 2548303

8. Inozemtcev A S 2014 Magazine of Civil Engineering 51 (7) pp 31-37

9. Inozemtcev A S, Korolev E V 2018 Advanced Materials Research 1040 pp 176-182

10.Hwang D, Khoshnevis B 2005 22nd International Symposium on Automation and Robotics in Construction p 6

11. Khoshnevis B, Bukkapatnam S, Kwon H, Saito J 2001 Rapid Prototyping Journal 7 pp $32-41$ 